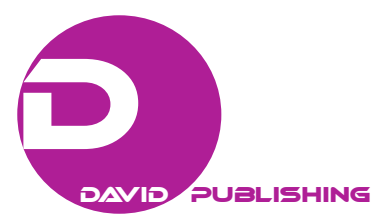

\title{
An Investigation of Second Language Writers’ Complex Dynamic Systems With Retrodictive Qualitative Modeling: Three Case Studies of Learners of Chinese
}

\author{
$\mathrm{IJu} \mathrm{Tu}$ \\ Southern Connecticut State University, USA
}

\begin{abstract}
Complex dynamic systems theory serves as a theoretical framework for its examination of the second language (L2) writing processes of three learners of Chinese. This study focuses on two research questions: 1. What attractor states do L2 writers encounter within complex dynamic systems and how do they respond to these states in their L2 writing discourses? and 2. What actions of self-organization do L2 writers exercise to co-adapt the complexities in their L2 writing discourses? It adopts retrodictive qualitative modeling, a three-step template for recognition of individuals' initial conditions, significant events, and attractor states. To analyze data from both linguistic and socio-cultural perspectives, the study draws on Gee to employ three analytic tools-identity, relation, and significance-to answer research questions regarding L2 writers' attractor states and self-organization. Three research findings show that the initial conditions of L2 writers' learning contexts affect attractor states, which influence L2 writing proficiency. The study also shows that an unsuccessful cultural repertoire can cause individuals to reposition themselves through acts of self-organization. This study investigates L2 writers' learning-to-write-processes, garnering insights that may improve L2 writers' self-directed learning and educators' instruction and curriculum design.
\end{abstract}

Keywords: second language writing, complex dynamic systems theory, retrodictive qualitative modeling, Chinese learning

\section{Introduction}

The American Council of Teaching Foreign Language (ACTFL) offers five standards as the means for foreign language teachers to create inclusive classroom settings and design effective curricula: communication, connections, cultures, comparisons, and communities. The "5Cs" are interlinked, providing a paradigm to encourage language learners to engage in a macro-system, avoiding the micro-dynamic in individual settings, which consists of heterogeneities inter- and intra- systems. The "5Cs" are designed for incorporation, engagement, and immersion with individuals’ heterogeneities (Standard Summary, 2019).

The pedagogical framework of 5Cs is mainly applied in environmental settings to social constructions as a way to explain individuals' external motivations. However, they have to do with individuals' macro- and micro- systems, including course contents, language proficiencies, and social interactions. Traditional second

I Ju Tu, Ph.D., assistant professor and Language Lab Director, World Languages and Literatures Department, Southern Connecticut State University. 
language acquisition (SLA) researchers design curriculum and develop instructions based on a linear model to predict students' learning outcomes with separate and independent subsystems for sound, meaning, and structure. Complex Dynamic Systems Theory (CDST) considers these subsystems as an emerging pool that dynamically affects individuals' language usages and that influences individuals' internal learning motivations (Dörnyei, Henry, \& MacIntyre, 2015; Verspoor \& Behrens, 2011). The complexities of individuals' heterogeneities internally (micro-system) and externally (macro-system) affect individuals' second language (L2) performances, which the "5Cs" cannot modularize for prediction.

CDST significantly values L2 learners' heterogeneities based on their impacts on individuals' learning trajectories. Larsen-Freeman and Cameron (2008), which initially developed CDST, has been widely discussed in the field of SLA. The theory questions over-simplified approaches of traditional SLA studies by making conclusions with variables manipulation and excluding changes in the language learning processes. CDST offers a transdisciplinary framework that emerges several theories to examine the L2 learning process and consider individuals' internal and external heterogeneities discussed in Table 1 (Larsen-Freeman, 2012).

Based on Table 1, the current gap of L2 writing studies and CDST can be argued that L2 writing differences are the result of interactions between external environments and internal mechanisms. Although scholars of L2 writing recognize the complexity of L2 writing process, the SLA research is presented in cutting dimensions of social-psychological, social-cultural, and socio-linguistics perspectives (Mitchell, Myles, and Marsden, 2013). In particular, the topic of the Second Language Written Corrective Feedback (L2WCF) is a well-received topic in scholarship since it is a daily classroom practice for language instructors. From 1930 to 2012, L2 WCF studies can be sorted out in text-analysis, the effect of WCF, students and teachers' perceptions, and meta-analysis (Ferris, 2012). Text-analysis focuses on written contents, including types of errors and patterns of errors that learners produce. Some scholars are interested in how WCF affects students' performance, whereas others are more toward students and teachers' perspectives on different types of WCF. While the former three types of studies are presented qualitatively, the meta-analysis offers a systematic matrix to recognize common factors in the given study. Even though L2 writing studies have been widely researched for decades, it is little to see L2 writing process has been investigated in a holistic and transdisciplinary way.

This study focuses on how individuals respond when attractor states occur and what self-organization they behave in their L2 learning to write processes. Learners' language proficiencies, cultural adaptations, educational settings, and social practices influence these processes (Bassetti \& Cook, 2005). Attractor states are a stable phenomenon that L2 learners intentionally/unintentionally present similarly and consistently (like fossilization) in L2 learning to write processes which are open and non-linear. Self-organization and co-adaption are innate abilities that human accommodates or assimilate within/between systems. To remain balanced in dynamic systems, such as L2 learning to write process, self-organization reflects the process that individuals emerge environmental complexities with their identities or language developments. Co-adaption is more related to individuals' actions toward different circumstances. Individuals' first languages (L1s) can be seen as initial conditions, which affects their learning to write process for co-adaption in different language systems.

In particular, the complexities of the Chinese writing system, learners' identities, and Chinese learning style have an impact on L2 learners of Chinese (Tu, 2016). Analyzing L2 learners' heterogeneities enables educators and students to explore individuals' internal mechanisms and external influences in complex dynamic systems. To produce this understanding, it is essential to ask: 
1. What attractor states do L2 writers encounter within complex dynamic systems, and how do they respond to these states in their $\mathrm{L} 2$ writing discourses?

2. What actions of self-organization do L2 writers exercise to co-adapt the complexities in their L2 writing discourses?

The purpose of this study aims to provide a qualitative data-driven perspective to understand how L2 learners respond to complex dynamic systems with the ability of self-organization and co-adaption in writing discourses and rethink individuals' internal mechanisms and external influences in the field of SLA.

\section{Overview of Complex Dynamic Systems Theory}

CDST is a relatively new theory in the field of SLA. It merges ecological theory, complexity theory, dynamic systems theory, chaos theory, and emergentism to provide a transdisciplinary framework to examine language learning trajectories of L2 learners (Dörnyei, 2014). Scholars who theorize concepts and develop research methods point out that language learning processes consist of various complex dynamic components in systems (Dörnyei, 2014; Hyland, 2016; Larsen-Freeman \& Cameron, 2008b; Verspoor, Bot, \& Lowie, 2011). Although the systems are interrelated, learning processes are neither predictable nor random, which is problematic for the adoption of traditional SLA research approaches (Dörnyei, 2014; Larsen-Freeman, 2012). When traditional SLA scholars design experiments or observe educational settings to predict learning outcomes, they focus on learners' psychological developments, including motivation, attitude, emotion, and learning aptitude. This approach has little likelihood of transforming pedagogy as they desire because it obscures the role of other factors that co-exist, are co-situated and co-engage in L2 learning trajectories.

CDST identifies "know-how," "know-where," and "know-when" as factors that affect L2 learners. "Know-how," psychological developments, has been the traditional focus of SLA scholars. "Know-where" considers the environment in which individuals are situated, which consists of interactions among external factors in learners' contexts. "Know-when” refers to timescale of individuals' life courses in the given context.

\section{Initial Conditions}

It is significant to recognize initial conditions, because they closely relate to individuals' heterogeneities and what Verspoor (2015) terms "the conditions of subsystems ... when the researcher starts measuring” (p. 45) by. Initial conditions serve as starting points for the given systems to track the following trends of learning paths. As Verspoor (2015) argued:

In language developmental research, initial conditions for each sub-system under investigation are intricately related to whether that particular sub-system is in transition, showing a great deal of variability, or has reached an attractor state where it is rather stable. (p. 39)

Individually, initial conditions can be examined in relation to internal mechanisms and external influences. Adapted from the work of Larsen-Freeman and Cameron (2008), Table 1 demonstrates how researchers might recognize an L2 writer's initial conditions in terms of psychological developments or internal mechanisms, and environmental demands, including socioeconomic status and social practices in different divisions (Larsen-Freeman \& Cameron, 2008b; Tu, 2016; Verspoor, 2015).

Pedagogically, students' initial conditions determine school replacement and instruction. School replacement allocates classes depending on students' L2 proficiency and provide the adequate scaffolding instruction. 
Therefore, individuals' initial conditions related to the interactions among students, teachers, peers, instructions, and curricula.

Table 1

Heterogeneity of L2 Writers' Social Lives and Language Use (Adapted from Larsen-Freeman and Cameron, 2008)

\begin{tabular}{|l|l|l|l|l|l|l|}
\hline Field (Extermal) & $\begin{array}{l}\text { Economic } \\
\text { (External ) }\end{array}$ & $\begin{array}{l}\text { Finance } \\
\text { (External })\end{array}$ & $\begin{array}{l}\text { Ecology } \\
\text { External })\end{array}$ & $\begin{array}{l}\text { Spoken } \\
\text { interaction } \\
\text { (External })\end{array}$ & $\begin{array}{l}\text { Classroom } \\
\text { language learning } \\
\text { (External })\end{array}$ & $\begin{array}{l}\text { Psychology } \\
\text { (Internal })\end{array}$ \\
\hline Heterogeneity & Tastes, incomes & $\begin{array}{l}\text { Risk, } \\
\text { preferences, } \\
\text { information }\end{array}$ & $\begin{array}{l}\text { Eating, nesting, } \\
\text { breeding, habits }\end{array}$ & $\begin{array}{l}\text { Language learning } \\
\text { background, } \\
\text { style, discourse, } \\
\text { topics }\end{array}$ & $\begin{array}{l}\text { Ability, } \\
\text { personalities, } \\
\text { learning demands }\end{array}$ & $\begin{array}{l}\text { Motivation prior } \\
\text { knowledge, } \\
\text { learning strategies }\end{array}$ \\
\hline $\begin{array}{l}\text { Students located } \\
\text { in different } \\
\text { universities, that } \\
\text { have different } \\
\text { resourses and } \\
\text { campus climates. }\end{array}$ & $\begin{array}{l}\text { Students will } \\
\text { have different } \\
\text { economic statuses } \\
\text { that will influence } \\
\text { how they value } \\
\text { their L2 learning } \\
\text { process differently. }\end{array}$ & $\begin{array}{l}\text { Students select } \\
\text { the setting in } \\
\text { which to study } \\
\text { language based } \\
\text { on their financial } \\
\text { situation. }\end{array}$ & $\begin{array}{l}\text { Ecology affects } \\
\text { tudents' writing } \\
\text { processes. Some } \\
\text { people are } \\
\text { productive in the } \\
\text { morning. }\end{array}$ & $\begin{array}{l}\text { Facial } \\
\text { expressions and } \\
\text { gestures affect } \\
\text { communication. }\end{array}$ & $\begin{array}{l}\text { Interactions with } \\
\text { instructors and } \\
\text { peers affect } \\
\text { students } \\
\text { knowledge } \\
\text { construction. }\end{array}$ & $\begin{array}{l}\text { Past experiences } \\
\text { determine how } \\
\text { students adapt to } \\
\text { new knowledge } \\
\text { and learning } \\
\text { motivations. }\end{array}$ \\
\hline
\end{tabular}

\section{Time Scales}

The notion of time scale relates to the rate of changes in systems. Despite systems ultimately reaching equilibrium states through self-organization, changes consistently occur and result in dynamic complexities in systems. Although CDST cannot predict changes in learning processes, time scales allow researchers to trace learning experience and create models that reflect the relationship between timescale and changes for individuals (De Bot, 2015; Dörnyei, 2014).

CDST denies causality because linear learning paths are hypothesized universally through variable manipulation, which positivism has misled (Van Lier, 2000). L2 development is not a linear path that can be measured or predicted. SLA recognizes that time is not conceptualized as absolute units because it is scaled and defined by external changes as day, night, week, hour, and minute. De Bot (2015) argued that "no scale ... is the scale for language development or even for components of it" (p. 31). Therefore, the notion of time scale is discussed in its relevance and interactions with human behaviors enacted from internal mechanisms or external influences. As De Bot (2015) described:

In the skills acquisition approach, language development can be decomposed into skills, [which can be deposed] into sub-skills .... [W] hereas it could be argued that the sum of the development of these skills is what constitutes developments, from a dynamic system theory perspective it is not the sum of these components, but their mutual influence on each other overtime that is the core of development. (p. 33)

CDST explains how time scale fundamentally interacts and affects rates of change in systems, and presents in different ways based its length and degree of interplay with individuals' heterogeneities. De Bot (2015) used running as an example to describe the conditions in which a timescale interacts with systems. Nonetheless, timescales do not always affect systems. For example, an individual person running does not affect the rotation of the earth even though both running and earth rotation occur concurrently. Therefore, timescale is not always meaningful in analysis, unless the rates of changes are relative to time.

\section{Attractor State}

An attractor state is defined as a pocket of stability and it results from a set of pattern outcomes that may 
reflect learners' intentions (Hiver, 2015). It affects how systems are presented in similar patterns dynamically and explains why the L2 learning processes reflect on complexities but eventually remain balanced. Hiver (2015) described attractor states that present as patterns, solutions, or outcomes; additionally, they are mostly categorical, theoretical, circumstantial, or phenomenological. The stillness of an attractor state closely relates to the initial conditions by which language learners are heterogeneously performed. Scholars compare L2 learning path to rolling ball as a way to illustrate attractor states from a physic perspective (Larsen-Freeman \& Cameron, 2008; Verspoor et al., 2011). If a L2 learning trajectory is like the path of a rolling ball in a room, it requires energy to keep the ball rolling. But if a ball's energy either transfers to an object, such as the lower floor, holes, and obstacles or lacks of power, it will stop. This illustration metaphorically presents how internal mechanisms and external influences affect the $\mathrm{L} 2$ learning process.

L2 learning process is a non-linear open system with varied parameters to support its dynamic complexity. Those parameters result from different attractor states depending on individuals' initial conditions, abilities of self-organization and co-adaption, contexts, and time. For instance, a well-designed lesson plan results in different learning outcomes in a class due to students' heterogeneities (see Table 1). Each student has a unique initial condition toward their target language and is affected by different attractors thus shapes different learning trajectories. If two students spend the same hours and use the same materials for final exam preparation. However, different outcomes may result from different attractors, including study skills, memory capacity, anxiety, life accidents, prior experience, etc. Attractor state explains how individuals perform patterns in some language tasks and irregularities in others.

Fossilization is an example of an attractor state that commonly occurs in an L2 learning curve (Verspoor et al., 2011). Fossilization occurs when a learner ceases to progress, a phenomenon cognitions or environments might spur. Scholarship has proposed various solutions to overcome fossilization, knowing the type of attractors is essential.

Adapting from Larsen-Freeman and Cameron' study (2008), Tu (2016) applied L2 writing scenarios to describe three types of attractors in CDST. Table 2 describes them.

\section{Self-Organization and Co-Adaption}

Humans have the innate ability to self-organize and co-adapt linguistic varieties within and between systems. If a L2 learner is regarded as an organism, receiving external inputs and developing internal intelligence is a recurring interactive process. Larsen-Freeman (2012) used communication between infants and caregivers as an example. Caregivers' feedback shapes the self-organization that shapes infants' language development. Both infants and caregivers co-adapt dynamically based on infants' language developments. Infants' degree of self-organization determines the range of language corpus and nonverbal signs infants and caregivers use to communicate.

CDST recognizes both self organization and co-adaption as individuals' abilities of maintaining equilibrium in states, but scholarship that employs the theory has not clarified what distinguishes these two concepts. The author proposes that agency is the key to distinguishing between them. Self-organization is the ability to recover spontaneously without an auxiliary agent in systems. Co-adaption requires consistent interaction with contexts in a timescale. Patterns, systems, or cycles that might stop a running ball or change its route are self-organization. Individuals must interact with the given contexts to adapt to the ongoing changes of self organization through co-adaption in order to balance shifting states (Hiver, 2015; Larsen-Freeman \& 
Cameron, 2008b).

Table 2

Three Types of Attractors in CDS (Adapted from Larsen-Freeman and Cameron, 2008)

\begin{tabular}{|l|l|l|}
\hline Types of attractors & Definition & Examples in L2 writing systems \\
\hline Fixed point attrcactor & $\begin{array}{l}\text { The simplest and most stable attractor } \\
\text { will always remain in a preferred state. }\end{array}$ & $\begin{array}{l}\text { Regular take-home writing assignments. Students } \\
\text { submit their assignments and teachers respond with } \\
\text { feedback in the following class. }\end{array}$ \\
\hline Cyslic (or closed loop) attractor & $\begin{array}{l}\text { Aperiodical mover which is mostly } \\
\text { likely to be seen as a dynmic } \\
\text { predator-prey system. }\end{array}$ & $\begin{array}{l}\text { The midterm and the final can be considered a cyclic } \\
\text { or closed attractor. It creates a competive climate in } \\
\text { the class in that period. }\end{array}$ \\
\hline Chotic (or strange) attractor & $\begin{array}{l}\text { An unpredictable but not random } \\
\text { attractor. It makes a system unstable. }\end{array}$ & $\begin{array}{l}\text { A bug flew into a student's laptop and the laptop could } \\
\text { go longer power on. All the written documents were } \\
\text { gone, including graduation thesis. }\end{array}$ \\
\hline
\end{tabular}

On one hand, self-organization refers to individuals' language development which results from various feedbacks of internal mechanisms or environmental influences. On the other hand, co-adaption indicates ones' ability to exercise agency to understand or solve the uncertainty in the present discourse. Hiver (2015) stated that "feedback is at the heart of self organization, and it plays a role in how a dynamic system moves toward or away from an attractor” (p. 22).

The author argues that self-organization and co-adaption are connected, because language learning is always contextualized, whether in classroom settings or digital forms. The affordances of self-organization and co-adaption vary and shift in different attractor states. In addition, the moves of self-organization and co-adaption are interactive.

\section{Context}

King (2016) highlighted the essence of context in CDST. Additionally, Larsen-Freeman and Cameron (2008) used CDST's perspective to explicit the changed nature of context, which refers to cognitive, cultural, physical, and social elements in the systems, because "any use of language can be seen as the soft assembly of language resources in response to some language using activities” (p. 204). In other words, contexts embed discursive and non-discursive resources, which interplay with individuals' ecologies. King (2016) defined:

[f]rom the micro-level contexts of intrapersonal narratives and interpersonal interactions, to the physical and social contexts of individual classrooms, in which instructional contextual features are embedded, right through and up to the broader sweep of macro-level socio-cultural and national contexts. (p. 2)

Combining a micro- and macro- perspective, Mercer (2016) concluded that context is "a dynamic, multifaceted system interconnected simultaneously with many other contextual systems." However, Mercer (2016) argued that contexts cannot be simply regarded as objects influenced by external settings; rather, individuals subjectively understand them through past experience and personal relationships with diverse networks in different systems.

$\mathrm{Tu}$ (2016) stated that agency is related to the changes that occur in the given contexts and L2 language learners who respond to those changes in various ways. Tu (2016) examined two types of fossilization that occurred in her study of Chinese language learners of English and Turkish. The first was caused by the changing nature of the teacher-student relationship. The second was caused by the difficulty of transferring between Turkish, English, and Chinese writing systems. When fossilization, an attractor state, occurs in an L2 
learning process, the context may determine how the learner exercises agency.

Scholars who discuss context in micro and macro perspectives rarely address the notion of time (King, 2016; Mercer, 2016; Tu, 2016). Although Bronfenbrenner (1979; 2004) added the notion of time to his early theorizations of ecological theory and bioecological theory, it is necessary to state the alignment of time and context coherently in order to analyze the complexities of the relationships within individuals' networks in aligned timescales.

\section{CDST Methodologies in L2 Writing Studies}

Scholars who apply CDST commonly utilize qualitative methods to investigate language learning (Dörnyei, 2014; Larsen-Freeman \& Cameron, 2008b; Mercer, 2016; Verspoor et al., 2011). Larsen-Freeman and Cameron (2008b) argued SLA is causal and emphasizes the importance of wholeness and situationess in CDST. Similarity, Dornyei (2014) argued that the assumption that the variables that affect the variables in the L2 learning process have linear relationships simplifies the models of SLA, which makes it impossible to determine the role each variable plays. As Dornyei (2014) described:

The most common research paradigms in the social sciences tend to examine variables in relative isolation rather than as part of a system or network, and most established quantitative data analytical procedures are based on linear rather than nonlinear relationships. (p. 80)

Hyland's (2016) suggestions invite researchers looking at L2 writing studies through the lens of CDST to choose a methodology based on the features of CDST and L2 writing studies. He reminds L2 writing researchers to consider "What we believe writing is," "the model of language we subscribe to," and "How we understand learning” (p. 117) before selecting a methodology. In addition, Larsen-Freeman and Cameron (2008a; 2008b) offered eight principles for research design for CDST. Table 3 shows the author's adaptation and clarification of each of these principles.

Based on Table 3, the eight research method principles of CDST are extended with examples in L2 writing discourse. In this study, RQM is chosen as a methodology majorly its three-step research template helps researchers inclusively approach the eight research method principles of CDST. The relevance of RQM and the CDST will be tailored in the next section.

\section{Retrodictive Qualitative Modeling (RQM)}

Dörnyei (2014) developed RQM as a methodology for CDST research. He observed that cutting interlinked relations among variables is problematic since discourses embed unpredictable changes. Therefore, RQM looks retrospectively to interpret rate of change, identify initial conditions, and observe the process of self organization in a time scale. As Dörnyei (2014) describes:

Although in dynamic systems, we cannot predict the behavior of the system with certainty, the essence of the proposed RQM approach is that we can understand salient patterns—or essential underlying mechanisms—associated with typical system outcomes. (p. 89)

Chan, Dornyei, and Henry (2015) defined the RQM process, thus: "First, we identify the end-states in system behavior and then work backwards in a retrospective manner to uncover the developmental trajectories that led to those settled states." Similarly, Dörnyei (2014) suggested a three-step research template for CDST research, which Chan et al. (2015) adapted for investigations of L2 motivational selves. The three-step is used for identifications of learners' initial conditions, contexts, and attractors in sequence in the 
following:

Table 3

Eight Principles for Researching CDST (Adapted from Larsen-Freeman and Cameron, 2008a; 2008b)

\begin{tabular}{|l|l|}
\hline Principles & Examples of variables in L2 wring discourse \\
\hline To think ecologically & L2 writers' micro-system (interactions with peers) and their socioeconomic status. \\
\hline To resist reductionism & Take every incident/written text into account to observe the following consequences. \\
\hline To be aware of changing relationships & Individuals' self-organizations reflect on writing strategy adjustments or motivations. \\
\hline To review reciprocal causality & Poor writing performance can be rather low motivation or a cause of demotivation. \\
\hline To avoid dichotomy & $\begin{array}{l}\text { L2 wring competence relates to internal and external factors. Emerging psychological } \\
\text { mechanisms and environmental influences. }\end{array}$ \\
\hline To consider timescales & $\begin{array}{l}\text { L2 writing is an ongoing process; therefore, framing a time scale helps researchers } \\
\text { analyze learning path in/between systems. }\end{array}$ \\
\hline To recognize rates of changes & $\begin{array}{l}\text { L2 writing process includes various linkages of diffenet variables including variables } \\
\text { of L2 writers’ heterogeneities. }\end{array}$ \\
\hline To investigate both stability and dynamic & $\begin{array}{l}\text { Stability and dynamic can co-exist or occur in sequence in L2 writing discourses. It is } \\
\text { necessary to investigate both and analyze systems' complexities. }\end{array}$ \\
\hline
\end{tabular}

Identifying salient student types in the classroom. Heterogeneities is a key feature of CDST, because it relates to initial conditions of systems ( $\mathrm{Tu}, 2016)$. Categorizing different types of language learners enable researchers to identify initial conditions of L2 learners. Chan et al. (2015) used the social categorization process to list several characteristics of L2 learners in terms of cognition, emotion, motivation, or behavior to sort out a collection of archetypes of $\mathrm{L} 2$ learners.

Identifying students who conform to the established prototypes and conducting interviews. Placing learners in the appropriate categories, which is a contextualized process that allows researchers to picture L2 learners' learning trajectories.

Identifying the most salient system components and the signature dynamic of each system. Capturing main components of the systems and identifying the patterns and signature dynamics, which is a process of analyzing the attractor states, a pattern of outcomes in L2 learners' learning trajectories.

The three-step template enables researchers to identify initial conditions, contexts, and attractor states. Although the three-step template offers an explicit approach to model an archetype of L2 learning characteristics, a lack of analytic tools make it possible to perform this model incoherently.

The three-step template offers an approach to anchor the significance of individuals' dynamic systems at a specific time scale. It allows researchers to look backwardly for individuals' initial conditions, ending state, and systems' interactions for contextualization. This methodology aligns with the eight principles of research design for CDST that Larsen-Freeman and Cameron (2008a; 2008b) suggest. The step one-Identifying salient student types in the classroom supports the principles of to resist reductionism and avoid dichotomy in the given learning discourse. The step two-Identifying students who conform to the established prototypes encourages researchers to review students' prototypes and reflect on the principle of being aware of changing relationships and recognizing rates of changes. The step three is to identify the most salient system components and the signature dynamic of each system. This is the most crucial step to achieve the rest of principles, including "thinking ecologically," "review reciprocal causality," “consider timescale,” and "investigate both stability and dynamic.” The three-step template enables researchers to identify initial conditions, contexts, and attractor states. Although the three-step template offers an explicit approach to model an archetype of L2 
learning characteristics, a lack of analytic tools make it possible to perform this model incoherently.

\section{Research Design}

Hyland (2016) reminded researchers to consider the definitions of writing before selecting a method. The foci of holistic and process-oriented perspectives of this study can be beneficial, because RQM serves as a methodology to examine L2 writing processes.

\section{Data Collection}

The author interviewed three learners of Chinese with L1s of English, Korean, and Turkish, respectively and investigated their Chinese writing for 15 weeks. Over the semester, they provided their L2 written assignments and talked about interactions with peers, instructors, or community members.

These three interviewees were selected due to their heterogeneous linguistic backgrounds and Chinese language learning trajectories. They provided different initial conditions as the start point for this study. Meanwhile, they had similar Chinese language proficiency when they used the same version of the textbook aligned with the level of intermediate high that ACTFL identifies. They were identified as salient students in this study, which fits in the framework of three-step of RQM.

The data collection process is conducted across 15 weeks (From July to October) and conducted internationally. The first half part of interviews (from July to the mid of August) was conducted on-site at Dragon University located in Shanghai city of China. The rest of the interviews were partially interviewed through online conferences due to different academic schedules among these three interviewees. The three interviewees, Kim, Cathy, and Linda, enrolled in different language programs affiliated with Dragon University. Kim attended a Chinese language program in one academic year; Cathy was admitted to master program at Dragon University in Fall but went to the prerequisite intensive language program in summer for language preparation; and Linda was in a summer language exchange program co-hosted by her mother institute, Lake University in the Midwest of United States, with Dragon University.

In this study, the author collected participants' Chinese written texts, interview transcripts, and the field notes. The author met with interviewees before they submitted their writing assignments, not only collecting the copies of texts, but also interviewing them about their writing processes and their thoughts about the assigned topics. Each week, the author asked questions about interviewees' writing processes and collected their responses/reflections from the previous weeks' assignments, which included teachers' feedback. The interview questions are listed in Table 5.

The author also asked questions about events in their daily lives, which were associated with language activities. The research process can be mapped as follows:

To align with a three-step template, data is selected through the criteria of significant events, changes, and themes, which also addresses his research interest. The author selects some data that addresses all three criteria and also some related to only one criterion. His goal is to synthesize what the interviewees describe across the criteria, rather than omit the data and select only those that address all three themes.

The interviewee was invited to submit their weekly Chinese writing assignments (10 papers per person) and talk about their writing processes (10 hours per person; one hour per week on average). Their assignments were handwritten or typed, depending on the interviewees' preferences. Semi-structured interviews were conducted and audio recorded on media stored in a secure database. The written texts were locked in storage. 


\section{Methodology}

RQM combines methodologies that scholars endorse for L2 writing research (Dörnyei, 2014; Hyland, 2016; Larsen-Freeman \& Cameron, 2008b), and therefore, the author used it to investigate interviewees' complex dynamic systems in L2 writing. The alignment between research questions and RQM is dedicated to the investigation of individuals' attractor states and self-organizations across systems. Additionally, Dornyei (2014) suggested QRM particularly can be used in strong attractor-governed phenomena, dynamic outcome patterns, and typical attractor conglomerates, which corresponds to research questions as well.

Table 4 lists narrative accounts of interviewees' initial conditions, attractor states, and self-organization following the instruction of three-step templates. The summaries of interviewees' Chinese learning processes identifies students' initial conditions. Since RQM is a trace-backward methodology, the analysis unfolds in the following sequence: outcome, initial conditions, attractor states, and self-organization (Chan et al., 2015).

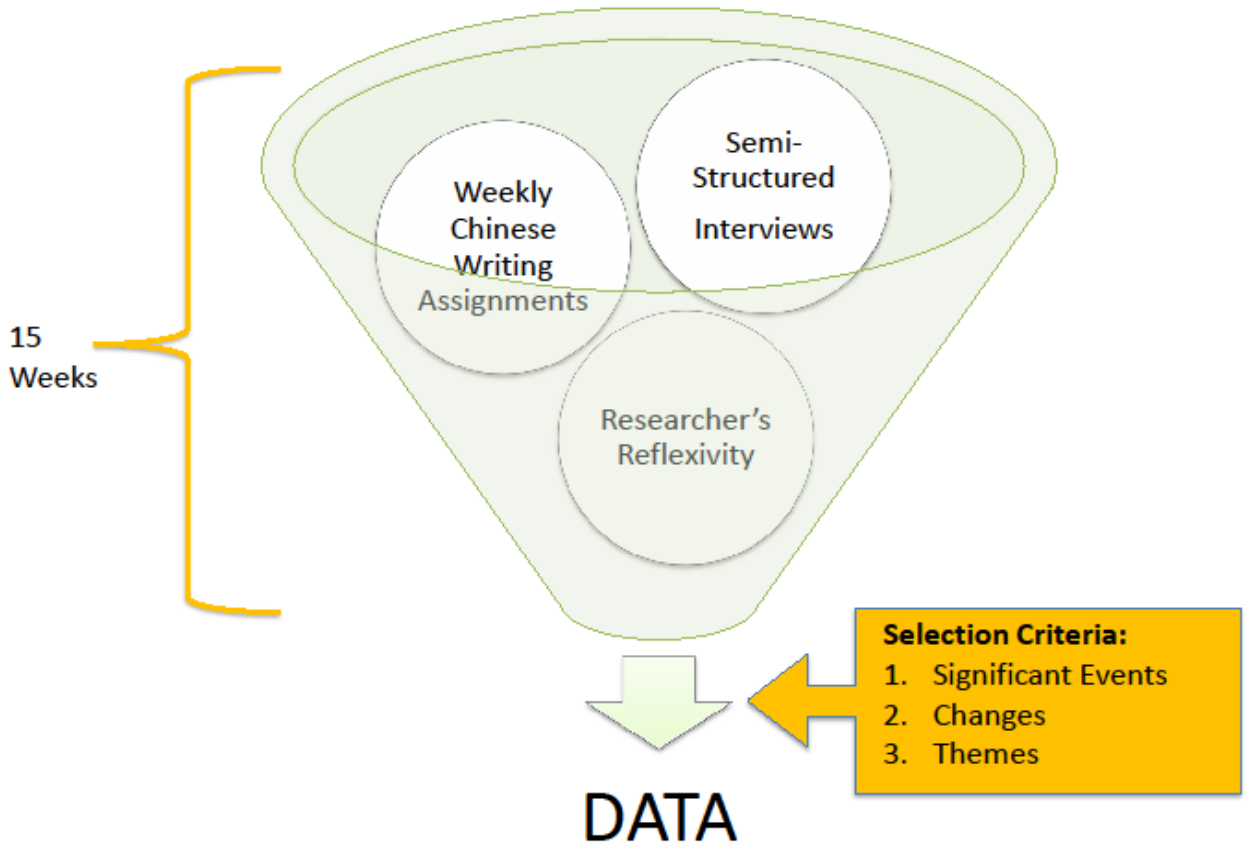

Figure 1. Data collection process and data selection criteria.

\section{Three-Step Templates}

Three participants were selected as interviewees. All were women who had been learning Chinese as an L2 for at least three years and were currently enrolled in college-level Chinese language courses or programs. The interview profiles in Table 4 address their learning styles, salient types of L2 writing, and significant events in their life courses. Below, their profiles address their initial conditions, attractor states, and self-organization. 
Table 4

Interviewees' Profiles

\begin{tabular}{|l|l|}
\hline Participant's name (Pseudonym) & Profile \\
\hline Kim & $\begin{array}{l}\text { Kim is Korean but strongly dislikes Korean culture. She left Korea after high school and } \\
\text { moved to Singapore to work. Two years later, she started her own business after she was laid } \\
\text { off from a previous job. Through self-learning, she speaks Japanese, Malay, and Mandarin. } \\
\text { She learned these languages for fun, not for academic success. She was reluctant to study } \\
\text { Chinese until she read a Chinese writer's prose by accident. Since then, writing in Chinese has } \\
\text { been a self-exploratory process. She regards writing as a liberation movement. }\end{array}$ \\
\hline Cathy & $\begin{array}{l}\text { Cathy is a prospective graduate student at "Dragon University" (pseudonym) in China. Before } \\
\text { starting her master's program, she studied Mandarin in China for two semesters. She is } \\
\text { originally from Turkey and studied English literature for her bachelor's degree. She provided } \\
\text { extensive reflections on her Chinese learning process, especially in relationship to reading and } \\
\text { writing. Her focus is on academic writing, and her writing proficiency is a significant concern } \\
\text { because her word recognitionis relatively weak. In addition, she was placed in a classroom } \\
\text { where all the other learners are Sinophone writing system users. As the only alphabet writer, } \\
\text { she felt the weight of social comparisons. }\end{array}$ \\
\hline Linda & $\begin{array}{l}\text { Linda is a college senior who is double majoring in political science and Chinese literature at } \\
\text { "Lake University" (pseudonym) in the United States. She is Caucasian. She is a native English } \\
\text { speaker and speaks French and Mandarin as her L2s. She started learning Chinese in college } \\
\text { and almost obtained her degree with a minor in the subject, but she ended up dropping the } \\
\text { final course that would have made the minor. She was determined, however, and worked very } \\
\text { hard to learn Chinese, because she wanted to work in China after graduation. Her dream was } \\
\text { to work as a translator for politicians. However, she worried her language proficiency could } \\
\text { become a challenge in her career. She also experienced a problem with cultural adaption, as } \\
\text { she offended her instructor, Mr. Lee, by writing material that was inappropriate. She decided } \\
\text { to quit Chinese and move on. }\end{array}$ \\
\hline
\end{tabular}

Table 5

Interview Protocol

\begin{tabular}{|c|c|}
\hline Question categories & Questions \\
\hline Family/language background & $\begin{array}{l}\text { Where are you from? } \\
\text { How long have you learned the Chinese language? } \\
\text { Do your family members speak a L2? } \\
\text { Besides Chinese and your native language, what other language experience do you have? }\end{array}$ \\
\hline Environmental/setting & $\begin{array}{l}\text { How is your relationship with peers? Or instructors? } \\
\text { How do you like instructions and curriculum of the program? } \\
\text { How was the class? } \\
\text { What would you suggest for this course? }\end{array}$ \\
\hline Learning/writing process & $\begin{array}{l}\text { How much time did you work on the first assignment? } \\
\text { How was the process? } \\
\text { Did you ask for help or find ways to complete your homework? } \\
\text { Do you read the feedback? How do you think about the feedback? } \\
\text { What difficulties did you encounter this week? } \\
\text { New learning difficulties? } \\
\text { New solution for study? } \\
\text { How was the project or assignment? } \\
\text { How did you study? Did it work? } \\
\text { Are you still interested in Chinese language? }\end{array}$ \\
\hline Reflections & $\begin{array}{l}\text { Why do you choose to study this language? } \\
\text { How has this language writing process affected you? } \\
\text { How do you think about the written feedback? } \\
\text { What are the similarities and differences between your first and second language? }\end{array}$ \\
\hline
\end{tabular}

\section{Findings and Discussions}

This section draws on the research findings and provides conclusions with respect to the research 
questions. It also describes the implications of these conclusions and provides direction for future studies.

\section{Attractor States Result From L2 Writers’ Initial Conditions}

Recognizing initial conditions relates to identifications of attractor states. Interviewees started their Chinese in different circumstances, settings, and contexts. Because of their differences, there were different types of attractor states in their learning trajectories.

Kim. Kim's initial conditions discouraged her pursuit of academic success. Kim describes higher education as a money-driven system. She labels higher education as a career-center regardless of students' interests and multiple intelligences. As she said:

College should be a place for people [who] know research and people know what they want to study. It is not a place to judge people .... Is that really a good system? I feel some people are just interested in one subject, but the test examines everything .... So, I do not like this system. If you go to college and choose the right major, you got a good job. If you got a wrong major, you do not get a good job .... A person's intelligence is what he wants to learn. Not, a college evaluates students and tells you what you should do.

Kim's unsuccessful k-12 schooling led her to refuse to build academic toolkits or meet teachers' expectations. These initial conditions made Kim believe that self-directed learning the only way to enhance her proficiency. She constantly emphasized that her poor Chinese resulted from her insufficient efforts, as she confessed,

I do not really work as hard as other people. I have to work hard and I do not mind dropping from the school. I want to learn by myself.

This explanation evidently referred to her refusal of the academic tool kit her instructor provided.

Kim preferred to learn independently without teachers' instructions. She ignored teachers' feedback on her writing but adopted a self-directed approach, such as reading particular Chinese books to improve her Chinese. She was unwilling to adapt her approach to university requirements. She spoke of feeling "sorry" for her teacher but being unwilling to listen to him. Her initial conditions stably present her learning state as a language lover but not an accountable learner.

Cathy. Cathy recognized two initial conditions that made it difficult for her to learn the Chinese writing system. First, she has been very successful learning to write in English, and expected to have the same ease in Chinese. Second, all of the other students in her classroom are Sinophone writing system users besides her. She said:

Chinese characters are so difficult for me ... I put my writing as the weakest [in the class], because I cannot memorize the characters.

Cathy aims to apply to graduate school in China and is extremely motivated. Cathy's initial conditions emphasize her weakness of word recognition. She can neither hand write characters correctly nor select the right characters when she types.

Linda. Linda's initial conditions were significantly related to her instructor-Mr. Lee. Prior to the term in which we spoke, Mr. Lee was her classroom instructor in Lake University and program coordinator in her summer exchange language program taking place in Shanghai China co hosted by Lake University and Dragon University. He was able to give her considerable attention over the summer, as she described:

I met him every day, [and] I had questions every day. I think he liked that. It made him feel good being a teacher. I think he found it was rewarding. I asked the most retarded questions. He loved these questions. He loves it. 
Linda also said that perhaps she was being "crazy.” Emotional words suggest the nature of her relationship with Mr. Lee, with whom she felt a close friendship. Her initial conditions thus related to this relationship, and as I will discuss, the discourses changed and shifted to an attractor state, and she was frustrated by the time of the study period.

\section{Attractor States Affect Chinese Writing Proficiency}

Kim, Cathy, and Linda encountered different attractor states that were affecting their L2 writing proficiency. In their complex dynamic systems, attractor states are culturally, linguistically, and socially presented and most likely to be recognized as significant events by interviewees.

Kim. Kim's attractor states were triggered when she read the writing of Ni-Kuang, a famous Chinese writer. His Christianity resonated with hers and she said that she felt Ni-Kuang had written just for her. She described her feelings about his books thus: "Now, I like writing, because when I write, I imag[in]e that someone fully understands me."

Reading prose became an attractor state, because it related to Kim's initial conditions. Kim is a self-directed language learner who is not comfortable in the school setting. The author's observations suggest a lack of an academic tool kit disadvantages her performance and network building, although she attributed her failure to a lack of intelligence:

If I have a chance, I would not go to college in Korea .... I am not qualified to do this ... I am very stupid. I read Chinese book. I understand when I read. But when I have to write, I do not remember, I cannot write .... I have to work harder, because I am stupid.

Kim's difficulties led her to question if instruction and curriculum could facilitate her learning. She found Chinese "boring" and said that her teacher should be working harder to help her "like” the language. "What you taught is not that important because language is a nature thing." Kim believes strongly in self-directed language learning and says she doesn't care about her teacher's feedback or her grade. She said:

Now, I like to write, because I feel I can share my secrets like Ni-Kuang did in his prose .... There are countless Chinese words. For writing, I work harder and step by step. To write something, I read a lot of characters ... [in] maybe one or two hours I can finish an essay. I have to think through and try harder to write something close to my thought[s].

Cathy. Cathy's attractor state occurs when recognizing her fossilization in Character recognition. With an L1 of Turkish and an L2 of English, Cathy feels left behind in a class of Japanese and Korean writers. This affects her attractor states and self-organization since she is under the stress of social comparison.

Cathy's initial condition was disadvantageous. Her teachers recommended character dictation practice, which she found unhelpful because she is an alphabet user. As she described:

Learning Chinese, you have to recognize words. For the Easterners, repetitively writing characters' work. Because they do not have to take extra time to understand the cultural context. But for me, being Western, there is no explanation.

Cathy kept practicing and using her network to improve her word recognition as a co-adaptive learning strategy to overcome the attractor states that she confronted. Reading the Chinese characters sectionally (i.e., radicals analysis) and constructing her knowledge with friends allowed her to get through the attractor states.

I read the textbook and make similar sentences, then replace the vocabulary .... You read the words individually, not all at once. I would tell them to circle the words that they recognize, then carefully see the characters. Similar words even have the same pronunciations, but mean different things .... That's why I invite my Korean or Japanese classmates to 
study together. They can also point out what radicals ${ }^{1}$ are related to emotions or feelings.

Linda. Linda withdrew from her Chinese class because of the attractor state in which she had conflicts with her instructor. The friendliness of their teacher-student relationship resulted in Linda putting inappropriate content in her Chinese essay. As she described:

For the word “雞巴” ${ }^{2}$. I do remember he said I should not have written it ... So, that was a misunderstanding of mine. I thought about not writing this word, but it is what I wanted to say ... I would say the most upsetting thing to him is about the language. And he was also very angry. I used another Chinese teacher's name. She is my third-year teacher. This is the thing that he was upset about.

Linda's positive learning experience over the summer set her initial condition, but two attractor states occurred afterward. First, Linda was frustrated when Mr. Lee was unable to offer her the attention she had given her during the summer. When she sought the same attention in the Fall when he was working as a lecturer, rather than as a program coordinator, he became angry and refused to talk about it.

The second attractor state stemmed from Linda's emphasis on friendship, which led her to think she could include inappropriate content in a classroom essay. As she explained,

I viewed him as my teacher and as my friend. He had known me since May. Even we talked more over the summer. He was my friend, and he knows a lot of personal things about me.

She admitted she would not have handed the same essay into a different teacher in the program, because she recognized it was inappropriate. She relayed that Mr. Lee refused to make eye contact with her in class after she offended him and that he would not allow her to apologize. She also felt that Mr. Lee became excessively demanding; she teared up in an interview saying he had pushed her "too hard."

To maintain balance in her systems, Linda dropped out of Chinese as an action of self-organization. She concluded that cultural differentiation was the key cause of her dropping the class. In order to move out of this uncomfortable attractor states, Linda decided to position herself in different contexts and drop the class. She concluded:

Mr. Lee is so traditional and I am so American. I do not think it is possible for [an] American to culturally understand Chinese people. Maybe it is my negativity, but I do not think it is possible anymore .... I have never thought things will go in this way. This is called either silence or violence. And I am definitely the more violent type. He is absolutely a silent type. Using the phrase, I am in the dog house.

\section{Repositioning as a Strategy of Self-Organization When Individuals Encounter Unsuccessful Cultural Repertoire Transformation}

All three interviewees repositioned themselves when unsuccessful transformations occurred in their Chinese writing discourses. Identity constructions are dynamically presented in initial conditions and end states because individuals exercise self-organizations to balance unstable systems. While L2 writers are capable of translating repertoire in different languages, they cannot fully transform it through L2 writing practice. Since they perform some conventions in Chinese, which results in a constantly shifting identity in their learning trajectories, different cultural repertoires affect L2 learners' identities. Kim repositioned herself as autonomous

\footnotetext{
${ }^{1}$ Radical is an indicator of Chinese character, which is similar to the prefix in English.

2 “雞巴” refers to the male reproductive organs in Mandarin.
} 
L2 writer, Cathy repositioned herself as a self-directed learner; and Linda repositioned herself as a female underprivileged student.

Kim. Kim has spent time in Singapore, Korea, and China, which led her to position herself as unique and free from social norms in a way that Cathy and Linda did not. She attended a college Chinese program, but the institutional regulations did not affect her identity construction. In undertaking Chinese writing activities, Kim joyfully repositioned herself as an autonomous L2 writer who could reach a Chinese-reading audience. She said:

I love learning languages. As long as something I am interested in, I will go for it. I learned Chinese by myself.

Writing in Chinese as a cultural repertoire encouraged Kim to transform her self-esteem. It was a healing process that allowed Kim to re-construct her identity and align with her life courses:

My writing ideas come from my mind. No TV program or book told me this stuff. This is an original idea that comes from my mind. I think a lot. I wrote, "Human is a great existence, but nature embraces human." My teacher circles the second sentence, because in Chinese, people do not say like this. But, this is my idea and I feel in this way. I do not really care how to make my idea sound right, because it is my idea. I feel sorry for my teacher, because I still keep creating my sentence.

Cathy. Cathy continually repositioned her western student identity in her Chinese writing process. She reflected on the Sinophone-oriented instruction and the troubles language interference caused her in two writing systems:

If I were a teacher, and my students are Western, I would introduce the structure of Chinese characters. And maybe give a more historical overview .... The evolution of the Chinese writing system would be introduced in my first class. It should be explained how the Chinese writing system has been categorized .... It would be easier for the Western students to understand.

Cathy sought academic Chinese resources that would support her L2 writing system. She repositioned herself from a teaching perspective and advised how Mandarin should be taught to non-Sinophone learners.

Cathy developed a self-directed learning approach to improve her word recognition. She had not transformed the Chinese repertoire into daily practice, because she needed more time to co-adapt Chinese writing system and Asian-centered instruction. As she said,

Learning Chinese, you have to recognize words. For the Easterners, repetitively writing characters' work. Because they dono $\mathrm{t}$ have to take extra time to understand the cultural context. But for me, being a Western, there is no explanation .... I circled the words and recognized then carefully saw the characters. Similar words even have the same pronunciations, but they mean different things. Because they have different radicals, so I always analyze the characters' structures, then guess their meanings.

Linda. Linda's mismanagement of the teacher-student relationship reflects the impact of Chinese conventions. Understanding repertoires in cross-cultural contexts proved confusing for her. She found herself struggling in both American and Chinese repertoires when she presented a gift to Mr. Lee as a way to ask his forgiveness. In this interaction, Linda literally and symbiotically performed a misplaced repertoire in different discourses. She had used her American repertoire to make fun, treating her instructor as a "friend." The gift signified her shift to a Chinese repertoire. Both repertoires were inappropriate from Mr. Lee’s perspective. As she explained:

I want to apologize. He is like, “Can I refuse being apologized to?” He kept cutting me off. I just wanted to express my apology. Give you a gift... And he looked bad. He refused the gift, like, twice ... He was just like "NO. I cannot accept the gift.” ... I need to show that he is the superior one. And [that] I respect him in the Chinese way. But it totally backfired 
like this in Chinese culture. This is the American culture. I would like to give you this gesture to the Chinese culture. And he is like "this is not appropriate. I am teaching in America."

Linda found that Mr. Lee was not comfortable with her use of either American or Chinese conventions. She realized that culture competence has to be included in language pedagogy. As she reflected:

As an American, I can go to his office and talk about my emotions ... I was not always inappropriate .... I thought I was capable. I thought I had been taught well in Chinese culture. I do not have a fluent culturally appropriate lingua. I have my English to transform to Chinese basically. That was difficult. Because it was like somebody consciously correcting you and being frustrated in a culturally sensitive manner .... But in the end, cultural things you need to be taught.

\section{Conclusions}

This study uses CDST as a theoretical framework to examine the L2 writing processes of three learners of Chinese. It adopts RQM as the methodology through a three step template for recognition of individuals' initial conditions, significant events, and attractor states and end states (Dörnyei, 2014).

This study lists five features of CDST related to L2 writing studies to assist data analysis. First, initial conditions recognize individuals' heterogeneities in terms of internal mechanisms and external influences, as shown in Table 1. Second, time scale is particularly important for CDST researchers to examine relations among systems and subsystems in a period. Third, the attractor state occurs when individuals remain stable for any reason. The three types of attractor state listed in Table 2 demonstrate that different types of attractor states lead to different L2 writing activities. Fourth, self-organization and co-adaption occur when L2 writers encounter unstable states, such as attractor states in learning trajectories. The former is an internal mechanism that individuals accommodate and assimilate for changing states; the latter indicates individuals' agency, which meta-cognitively adapts when different states occur simultaneously. Ultimately, context is multi-faceted in individuals' learning processes, which includes discursive and non-discursive interactions. Future considerations of contexts of L2 writers' writing systems should examine micro and macro phenomena in their learning trajectories.

Researching findings are presented through RQM methodology developed for CDST investigation. In particular, a three step template categorizes data, and three analytic tools of discourse analysis are used for analysis. The first finding affirms the importance of initial conditions of L2 writers' learning contexts since they are the start points of attractor states. Without investigation of initial conditions, attractor states, such as fossilization are barely apparent, since initial conditions are base states for comparison with the following states.

The second finding shows that attractor states influence L2 writing proficiency. Kim was not motivated to learn to write Chinese until she read a Chinese writer's prose. She argued that the academic system affected her authorship as a writer. Academic calendar and institutional standards ran as cyclic attractors that Kim was not ready to adapt to the system. Her proficiency was not enhanced by what the institution offered but her self-study. Cathy's struggle with the Chinese writing system affects her performance. The initial conditions of her first (Turkish) and second (English) language writing system became a fixed attractor in her learning ecology. In addition, the comparative learning process with peers whose L1s are Sinophone writing system became a cyclic attractor forcing Cathy to exercise self-organization to enhance writing proficiency. Linda's rapidly changing teacher-student relationship over the summer affects her learning trajectory, and it was an unpredictable chaotic attractor discontinuing her Chinese language learning. In sum, those attractors influence 
how individuals exercise their acts of self-organization.

The last finding shows that an unsuccessful cultural repertoire can cause individuals to reposition themselves through acts of self-organization. Kim repositioned herself from an unskillful student to an L2 writer because reading Chinese books help her construct her authorship. She self-organized her learning goal and developed alternate learning approaches within the institutional setting. Cathy repositioned herself as a teacher and advised teachers of Chinese as a second language to introduce background on the Chinese writing system to alphabet users. Her acts of self-organization included joining a study group to mentor her progress and reminding her instructors for her learning needs. Linda shifted her student identity to a female identity to rationalize Mr. Lee's anger for her inappropriate writing content. She tried multiple times and different ways to stabilize the chaotic attractors that Mr. Lee created her learning system. However, she failed in self-organization in her learning system, so she dropped the Chinese course to maintain balance in her life courses.

Exploring L2 writers' complex dynamic systems benefits both educators and L2 learners in terms of recognizing language learners' initial conditions, attractor states, and acts of self-organization or co-adaption. For educators, knowing the connections between individuals' micro- and macro- systems assists language educators in curriculum design and instruction, and ultimately reach the goals of 5Cs that the American Council of Teaching Foreign Language has identified as crucial for an inclusive language learning environment. For L2 learners, understanding complex dynamic systems enables L2 learners to mentor the trajectories of L2 writing processes and improve self-directed learning strategies.

\section{References}

Bassetti, B., \& Cook, V. (2005). An introduction to researching second language writing systems. In B. Bassetti and V. Cook (Eds.), Second language writing systems (pp. 1-67). Clevedon, UA: Multilingual Matters.

Bronfenbrenner, U. (1979). The ecology of human development: Experiments by nature and design. Cambridge, MA: Harvard University Press.

Bronfenbrenner, U. (2004). Making human beings human: Bioecological perspectives on human development (1st ed.). Sage Publications, Inc.

Chan, L., Dornyei, Z., \& Henry, A. (2015). Learner archetypes and signature dynamics in the language classroom: A retrodictive qualitative modelling approach to studying L2 motivation. In Z. Dornyei, P. MacIntyre and A. Henry (Eds.), Motivational dynamics in language learning (pp. 238-259). Tonawanda, NY: Multilingual Matters.

De Bot, K. (2015). Rates of change: Timescales in second language development. In Z. Dornyei, P. MacIntyre and A. Henry (Eds.), Motivational dynamics in language learning (pp. 29-37). Tonawanda, NY: Multilingual Matters.

Dörnyei, Z. (2014). Researching complex dynamic systems: "Retrodictive qualitative modelling” in the language classroom. Language Teaching, 47(1), 80-91.

Ferris, D. (2012). Written corrective feedback in second language acquisition and writing studies. Language Teaching, 45(4), 446-459.

Gee, J. P. (2010). How to do discourse analysis: A toolkit. New York, NY: Taylor \& Francis.

Gee, J. P. (2011). Social linguistics and literacies: Ideology in discourses (4th ed.). New York, NY: Routledge.

Hiver, P. (2015). Attractor states. In Z. Dörnyei, P. MacIntyre and A. Henry (Eds.), Motivational dynamics in language learning (pp. 20-28). Tonawanda, NY: Multilingual Matters.

Hyland, K. (2016). Methods and methodologies in second language writing research. System, 59, 116-125.

King, J. (2016). Introduction to the dynamic interplay between context and the language learner. In J. King (Ed.), The dynamic interplay between context and the language learner (1st ed., pp. 1-10). New York, NY: Palgrave Macmillan.

Larsen-Freeman, D. (2012). Complex, dynamic systems: A new transdisciplinary theme for applied linguistics? Language Teaching, 45(2), 202-214. https://doi.org/10.1017/S0261444811000061 
Larsen-Freeman, D., \& Cameron, L. (2008a). Complex systems and applied linguistics. New York, NY: Oxford University Press. Larsen-Freeman, D., \& Cameron, L. (2008b). Research methodology on language development from a complex systems perspective. The Modern Language Journal, 92(2), 200-213.

Mercer, S. (2016). The contexts within me: L2 self as a complex dynamic system. In J. King (Ed.), The dynamic interplay between context and the language learner (1st ed., pp. 11-28). New York, NY: Palgrave Macmillan.

Norton, B. (2013). Identity and language learning: Extending the conversation (2nd ed.). Bristol: Multilingual Matters.

Standard Summary. (2019, June 6). Retrieved from https://www.actfl.org/publications/all/world-readiness-standards-learning-languages/standards-summary

Tu, I. J. (2016). Understanding world language writing practice: A transdisciplinary contribution from discourse analysis and complex dynamic systems theory (Doctoral dissertation).

Van Lier, L. (2000). From input to affordance: Social-interactive learning from an ecological perspective. In J. Lantolf (Ed.), Sociocultural theory and second language learning (pp. 245-259). New York, NY: Oxford University Press. Retrieved from http://eslenglishclassroom.com/Art-03.pdf

Verspoor, M. (2015). Initial conditions. In Z. Dornyei, P. Maclntyre and A. Henry (Eds.), Motivational dynamics in language learning (pp. 38-46). Tonawanda, NY: Multilingual Matters.

Verspoor, M., Bot, K. D., \& Lowie, W. (2011). A dynamic approach to second language development: Methods and techniques. Amsterdam, Philadelphia: John Benjamins Publishing.

Vygotsky, L. S. (1986). Thought and language (Revised ed.). The MIT Press. 